O espaço na vida social 



\title{
O espaço na vida social: uma introdução
}

\author{
FRAYA FREHSE
}

$\mathrm{E}$ STE DOSSIÊ visa familiarizar os leitores de ESTUDOS AVANÇADOS com quatro textos seminais do século XX acerca de uma linha investigativa que, embora antiga na história da sociologia, apenas ao longo das últimas décadas tem merecido uma atenção mais sistemática da disciplina. É interesse cognitivo pela dimensão espacial das relações e práticas sociais, com base no pressuposto de que o espaço nem se restringe a substrato físico da pesquisa empírica, nem é mera abstração metafórica da reflexão teórica.

Desse ponto de vista, o espaço não é somente, de um lado, algo "lá fora”, que nos envolve como se fosse uma "caixa” - imagem, aliás, utilizada há tempos por Albert Einstein para contrapor-se justamente a tal concepção de espaço, da qual Isaac Newton foi importante porta-voz. De outro lado, a noção não constitui simples recurso lógico mobilizado para a apreensão conceitual da dinâmica das relações e interações sociais: uma categoria comum na sociologia é "espaço social", empregada de modo pioneiro, nos anos 1920, pelos sociólogos Pitirim Sorokin e Leopold von Wiese.

Quando o foco se dirige para o papel do espaço na vida social, podem ser diversos os aportes teóricos e metodológicos, mas o pressuposto parece ser um só. Embora não sempre de modo explícito, atravessa campos de conhecimento bastante diversos do mundo ocidental a concepção de que o espaço é um conjunto de relações.

Ocorreriam tais relações entre bens materiais apenas, entre esses e os imateriais, ou seres humanos e coisas, quando não só entre seres humanos? Dá-lhe debate. Ou, por outra: seriam tais relações de contiguidade, enquanto o tempo seria marcado por relações de sequência, como preconizou há séculos Gottfried Wilhelm Leibniz? Mais debate. Enfim, proviriam tais relações dos próprios seres humanos, dos vínculos entre estes e as coisas, das coisas "em si", da materialidade física de tudo isso? Mais debate ainda. De fato, foi em torno de questões como essas que se consolidou no pensamento ocidental ao longo dos séculos uma seara ampla de discussões teóricas, entrelaçando física, filosofia, arquitetura, artes, geografia e ciências sociais (Dünne; Günzel, 2006).

Ora, se o espaço é um conjunto de relações, a sociologia tem o que dizer. O "ponto de referência” do sociólogo, afinal, "não é o organismo, sua estrutura e mecanismos, mas a própria teia de interações e de relações sociais" (Fernandes, 1970, p.20-1). Então, como as relações que constituem o espaço se articulam 
com tal "teia"? Tudo depende da definição de espaço, e da "teia" - mais assunto para tinta correr...

Realmente, reflexões sociológicas sobre a dimensão espacial da vida social são em parte já centenárias. Um texto pioneiro nesse sentido abre justamente este dossiê. É o ensaio do filósofo e sociólogo alemão Georg Simmel (18581918 ) sobre "A sociologia do espaço", concluído no outono de 1902 (Kramme et al., 1995, p.355), pouco antes de, no inverno, ser elaborado o atualmente já clássico ensaio sobre "As grandes cidades e a vida do espírito" (Simmel, 2005). Abordando o espaço numa perspectiva interacional, o texto aqui traduzido integra um projeto de livro sobre os fundamentos da sociologia anunciado num artigo de 1894. Publicado em 1903, ele faz par com um segundo ensaio do mesmo ano cujo título pode ser traduzido como "Sobre projeções espaciais de formas sociais" (Simmel, 1995a). Esse ensaio foi resenhado, na ocasião, por Émile Durkheim (1902-1903, p.646-7). Fundidos e retrabalhados, os dois textos viraram o nono capítulo - em tradução livre, "O espaço e os ordenamentos espaciais da sociedade" - do opus magnum de Simmel (1995b) sobre a sociologia, texto até agora só traduzido integralmente para o espanhol (Simmel, 1986).

Poucos anos depois, era o próprio Durkheim (1994) que, de modo mais pontual, oferecia uma teorização própria acerca do espaço. Retomava reflexões prévias suas acerca da "morfologia social” (Durkheim, 1899, p.520-31).

A despeito do pioneirismo das contribuições desses autores, elas permanecem esparsas numa trajetória disciplinar no âmbito da qual a noção de espaço constituiu antes pressuposto do que objeto epistemológico próprio. $\mathrm{Na}$ sociologia tem prevalecido um "uso implícito" de categorias espaciais; raramente o espaço foi assumido "explicitamente como tema" (Schroer, 2008, p.131).

É com o avanço da globalização econômica, a partir das duas décadas finais do século XX, que essa última tendência vem ganhando corpo. O processo implica uma desespacialização das relações sociais que vai de mãos dadas com a multiplicação de espaços outros, antes insuspeitados, reais e virtuais, locais e globais (Berking, 1998). Mesmo na geografia, historicamente pioneira no estudo do espaço, há quem associe os idos contemporâneos ao "spatial turn" (Soja, 1989, 1996). Já na sociologia, o interesse renovado pela dimensão espacial da vida social repercutiu em primeira instância nos embates em prol da diferenciação entre a modernidade, que teria privilegiado a categoria "tempo", e a pós-modernidade, sinônimo da "espacialização do temporal" (Jameson, 1991, p.156). Do cerne dessa discussão brotaram enfoques como o das modernidades múltiplas e os estudos pós-coloniais.

Nesse contexto, reassumiram relevância ímpar abordagens das décadas anteriores. Além da "Sociologia do espaço" de Simmel, vertida então pela primeira vez para o inglês, e por sociólogos explicitamente "pós-modernos" (Frisby; Featherstone, 1997), penso nas contribuições que constituem o segundo e o terceiro textos deste dossiê, em sua ordem cronológica de aparição. Trata-se, 
de um lado, do ensaio do filósofo francês Michel Foucault (1926-1984) "De espaços outros". Foi elaborado como palestra para arquitetos na Tunísia em 1967, durante uma estada do pensador ali como professor visitante, e Foucault só autorizou a publicação pouco antes de morrer - embora não tenha chegado a fazer a revisão do manuscrito, trazido a público numa exposição em Berlim (Foucault, 1986) e, mais tarde, vertido para o inglês. De outro lado, refiro-me à ênfase teórica e metodológica do filósofo e sociólogo francês Henri Lefebvre na "produção do espaço". Embora desenvolvida amplamente no livro intitulado La production de l'espace (Lefebvre, 2000), a perspectiva foi sintetizada pelo autor no "Prefácio" que integra a obra a partir da segunda edição, de 1985. Aqui, tal texto é publicado pela primeira vez em português - coexistindo com uma versão inglesa (Lefebvre, 2003).

Com efeito, é sobretudo desde os anos 1980 que sociólogos vêm dialogando mais intensamente com a leitura de geógrafos anglo-saxônicos (em particular Harvey, 1989; Soja, 1989) sobre La production de l'espace (Sassen, 1991; Zukin, 1991). Isso enquanto outros, como o francês Pierre Bourdieu no texto que fecha este dossiê, recuperam teorizações prévias suas sobre o chamado espaço social, a fim de explicitar de maneira até então inédita os vínculos que esse nutriria com o espaço físico.

Nesse caso, tal empenho se concretizou como paper para uma conferência sobre "pobreza, imigração e marginalidade urbana em sociedades avançadas" ocorrida em Paris em maio de 1991, tendo sido revisto à mão pelo próprio autor, mas nunca publicado em francês; só em alemão (Bourdieu, 1991) e, agora, em português. As reflexões ali contidas foram, contudo, aprofundadas: em versão transformada, o texto integra o capítulo "Efeitos de lugar" de $A$ miséria do mundo (Bourdieu, 1997).

Todas essas são movimentações que, na última década, têm repercutido em especial no cenário acadêmico de língua alemã (cf. a respeito Frehse, 2010). Já no debate sociológico brasileiro essa discussão é bem mais rarefeita. Mesmo nutrindo significativos pontos de contato com essa história mais ampla de reflexões sobre o espaço na vida social, as conceituações das ciências sociais brasileiras a respeito são esparsas. Elas aparecem em certo pensamento social do início do século XX (cf. a respeito Lima, 1999; Maia, 2008), aprofundando-se no contexto de institucionalização da sociologia no Brasil (cf. em especial Freyre, 2000a, 2000b; DaMatta, 1997a, 1997b; Martins, 1992, 1997), e, a partir da década de 2000, o papel do espaço nas relações sociais é perseguido de maneira mais sistemática em termos conceituais, e não só empíricos (cf. Arantes, 2000; Leite, 2004; Frehse, 2005, 2011; Marques, 2005, 2011; Telles; Cabanes, 2006; Martins, 2008; Telles, 2009).

Considerando tal desencontro, este dossiê visa promover especialmente o debate sociológico brasileiro sobre essa temática congregando textos que expressam concepções de espaço as quais inspiraram tendências teóricas relevantes 
dessa história que acabo de sintetizar. Embrenhar-se nos espaços interacionais de Simmel é abrir-se à possibilidade de reencontrá-los, décadas depois, nas inspiradas interpretações de um Alfred Schütz sobre o estranho, e de Erving Goffman sobre a comunicação não verbal. Quanto aos espaços relacionais de alocações que marcam Foucault, não espanta que eles permeiem sobretudo o debate pós-moderno sobre o espaço. Já a influência do espaço dialético de Lefebvre sobre o debate contemporâneo sobre o "direito à cidade" é evidente. Enfim, também a relação homológica entre espaço social e físico subjacente à noção de "efeito de lugar" ressoa no debate urbano atual sobre pobreza e segregação.

Explicitados todos esses aspectos, fica claro que o dossiê se dirige a quem quer que se interesse por espaço, e por vida social. Para tanto, nada como aludir, por fim, ao processo de tradução desses textos, marcados em parte pela transitoriedade estilística própria dos manuscritos (em Foucault e Bourdieu). Para além de todas as dificuldades teóricas e metodológicas envolvidas no conhecimento do espaço na vida social, existe ainda uma peculiaridade linguística de fundo a tornar tão complexa a abordagem da temática. A palavra "espaço" se insere em uma linhagem de termos que engloba o francês "espace", além de outras línguas românicas e o inglês, mas não o alemão, cujo termo correspondente é "Raum". $\mathrm{E}$ isso embora os significados cotidianos até hoje correntes de ambas as palavras tenham se estabelecido na transição da Idade Média para a Era Moderna (Dünne; Günzel, 2006, p.10). Mas eles são bem diversos: enquanto o francês "espace", do latim spatium, remete a espaço de livre movimento e a intervalo temporal, "Raum" tem, como explicitam Dünne e Günzel (2006), um evidente vínculo territorial, "sendo associado à atividade de abrir clareiras em terras quaisquer para fins de povoamento, ou à instalação de um acampamento militar - além, de em termos metonímicos, designar a própria povoação" (ibidem).

Como sutilezas desse tipo se aplicam também a outros termos espaciais presentes nos quatro textos ("lugar", "local”, "posição" etc.), é fácil ser levado a acreditar, como o filósofo Fritz Mauthner no verbete "Raum" de seu dicionário crítico-linguístico de conceitos filosóficos, de 1910, que "nossas representações de espaço não são mais do que um tipo especial de língua" (Dünne; Günzel, 2006, p.9). Aqui, não foi tanta a radicalidade, mas significativo o desafio das traduções: respeitar a literalidade do texto e o estilo literário do autor - filhos, ambos, de tempos e espaços específicos -, sem descurar da tarefa de tornar compreensíveis os conteúdos ao leitor de língua portuguesa. Para esse desafio pude contar com o apoio incondicional de Rainer Domschke e Ana Cristina Nasser, a quem agradeço.

Mas sou grata também a José de Souza Martins, a Alfredo Bosi e a Dario Luis Borelli, pelo incentivo em relação ao projeto do dossiê; e a Jean Pavlevski, a Marie-Christine Rivière e a Francisco Bilac Pinto Filho, por autorizarem a tradução e a publicação respectivamente dos textos de Lefebvre, de Bourdieu e de Foucault em ESTUDOS AVANÇADOS. 
Referências

ARANTES, A. A. Paisagens paulistanas. Campinas: Editora da Unicamp, 2000.

BERKING, H. Global flows and local cultures. Über die Rekonfiguration sozialer Räume im Globalisierungsprozeß. Berliner Journal für Soziologie, v.8, n.3, p.381-92, 1998.

BOURDIEU, P. Physischer, sozialer und angeeigneter Raum. In: WENTZ, M. (Org.) Stadt-Räume. Frankfurt; New York: Campus, 1991. p.25-34.

Efeitos de lugar. In: BOURDIEU, P. (Coord.) A miséria do mundo. Petrópolis: Vozes, 1997. p.159-66.

DAMATTA, R. Carnavais, malandros e heróis. Rio de Janeiro: Rocco, 1997a.

A casa é a rua. Rio de Janeiro: Rocco, 1997b.

DÜNNE, J.; GÜNZEL, S. (Org.) Raumtheorie. Frankfurt a. M.: Suhrkamp, 2006.

DURKHEIM, E. Morphologie sociale. L'Année Sociologique, ano 2, p.520-32, (18971898), 1899.

Resenha de "Über raumliche projectionen socialer Formen [sic]", de G. Simmel. L'Année Sociologique, ano 7, p. 646-7, 1902-1903.

Les formes élémentaires de la vie réligieuse. Paris: Quadrige; Puf, 1994.

FERNANDES, F. Elementos de sociologia teórica. São Paulo: Edusp; Rio de Janeiro: Companhia Editora Nacional, 1970.

FOUCAULT, M. Of other spaces. Diacritics, v.16, n.1, p.22-7, 1986.

FREHSE, F. O tempo das ruas na São Paulo de fins do Império. São Paulo: Edusp, 2005.

Blickwechsel: Zur deutschen Stadtsoziologie aus brasilianischer Perspektive.

In: KOLLOQUIUM “BLICKWECHSEL”, 2010.

Ô da rua! O transeunte e o advento da modernidade em São Paulo. São Paulo: Edusp, 2011.

FREYRE, G. Casa-grande \& senzala. Rio de Janeiro, Record, 2000a.

. Sobrados e mucambos. 12.ed. Rio de Janeiro: Record, 2000b.

FRISBY, D.; FEATHERSTONE, M. (eds.). Simmel on culture. London; Thousand Oaks; New Delhi: Sage, 1997.

HARVEY, D. The condition of postmodernity. Oxford-UK; Cambridge-Ma.: Blackwell, 1989.

JAMESON, F. Postmodernism. Durham: Verso, 1991.

KRAMME, R.; RAMSTEDT, A.; RAMSTEDT, O. Editorischer Bericht. In: SIMMEL, G. Aufsätze und Abbandlungen 1901-1908. Frankfurt a. M.: Suhrkamp, 1995. v.1, p.351-66.

LEFEBVRE, H. La production de l'espace. 4.ed. Paris: Anthropos, 2000.

Preface to the new edition. In: ELDEN, S.; LEBAS, E.; KOFMAN, E. (Org.)

Henri Lefebvre: Key writings. London; New York: Continuum, 2003.

LEITE, R. P. Contra-usos da cidade. Campinas: Editora da Unicamp; Aracaju: Editora UFS, 2004.

LIMA, N. T . Um sertão chamado Brasil. Rio de Janeiro: Revan, 1999. 
MAIA, J. M. E. A terra como invenção. Rio de Janeiro: Jorge Zahar Editor, 2008.

MARQUES, E. C. Elementos conceituais da segregação, da pobreza urbana e da ação do Estado. In: MARQUES, E. C.; TORRES, H. (Org.) São Paulo: segregação, pobreza e desigualdades sociais. São Paulo: Senac, 2005. p.19-56.

2011.

Redes sociais, segregação e pobreza. São Paulo: Editora Unesp; CEM-Cebrap,

MARTINS, J. de S. Subúrbio. São Paulo: Hucitec; São Caetano do Sul: Prefeitura de São Caetano do Sul, 1992.

Fronteira. São Paulo: Hucitec, 1997.

A aparição do demônio na fábrica. São Paulo: Editora 34, 2008.

SASSEN, S. The global city. Princeton: Princeton University Press, 1991.

SCHROER, M. Bringing space back in - Zur Relevanz des Raums als soziologischer Kategorie. In: DÖRING, J.; THIELMANN, T. (Org.) Spatial turn. Bielefeld: Transcript, 2008. p.125-148.

SIMMEL, G. Über räumliche Projektionen socialer Formen. In: Aufsätze und Abhandlungen 1901-1908. Frankfurt a. M.: Suhrkamp, 1995a. v.1, p.201-20.

Der Raum und die räumlichen Ordnungen der Gesellschaft. In: Soziologie. Frankfurt a. M.: Suhrkamp, 1995b. p.687-790. p.643-740.

El espacio y la sociedad. In: Sociología 2. Madrid: Alianza Editorial, 1986.

. The sociology of space. In: FRISBY, D.; FEATHERSTONE, M. (Org.). Simmel on culture. London: Thousand Oaks; New Delhi: Sage, 1997. p.137-70.

As grandes cidades e a vida do espírito. Mana, Rio de Janeiro, v.11, n.2, p. 577-591, 2005.

SOJA, E. W. Postmodern geographies. London; New York: Verso, 1989.

Thirdspace. London; New York: Blackwell, 1996.

TELLES, V. da S. A cidade nas fronteiras do legal e ilegal. Belo Horizonte: Argumentum, 2009.

TELlES, V. da S.; CABANES, R. (Org.) Nas tramas da cidade. São Paulo: Associação Editorial Humanitas, 2006.

ZUKIN, S. Landscapes of power. Berkeley: University of California Press, 1991.

Fraya Frehse é professora do Departamento de Sociologia da USP, onde coordena o Núcleo de Estudos e Pesquisas em Sociologia do Espaço (Nespe), além de pesquisadora colaboradora do Núcleo de Apoio à Pesquisa "São Paulo: Cidade, Espaço, Memória” da USP (NAP-SP). @ - fraya@usp.br

Recebido em 26.9.2013 e aceito em 5.10.2013.

I Faculdade de Filosofia, Letras e Ciências Humanas, Departamento de Sociologia, Universidade de São Paulo, São Paulo/SP, Brazil. 